\title{
Developing a Forensic Framework for Failures in Reinforced Concrete Buildings
}

\author{
Mohammed Arafa, Husam Wadi, Mamoun Alqedra
}

\begin{abstract}
There is not yet a universal forensic framework used for concrete buildings failures with detailed legal responsibilities; hence, there is a significant gap in the knowledge in this respect. This study seeks to fulfill this gap by developing a forensic framework for conducting forensic evaluation of failures occurred in reinforced concrete structures. Such framework would support engineers and interested experts in assessing forensic structural failures in a systematic and professional way. The developed framework consists of five stages; each comprises steps that show the events inherited in a variety of tasks. A key finding that emerge in this study suggests that the proposed framework includes identification of all types of collapses and failures within concrete buildings as well as shedding light on major and/or minor responsibilities of the failures. The established framework is compared with frameworks proposed by other researchers. Further, the developed framework is tested by applying to a documented local building collapse case. One of the main benefits of the developed framework is the fact that the legal responsibilities stage is connected to causes of failure through evidence based-facts.
\end{abstract}

Index Terms-Failure Safety \& hazards, Structural frameworks, Buildings, structures \& design

\section{INTRODUCTION}

Forensic engineering can be defined as the application of engineering sciences to the investigations of failures and/or performance issues. Therefore, forensic engineering deals not only with technical expertise but also with knowledge of the legal procedures. In this context, forensic structural and/or civil engineers have the role of identifying the technical causes that induce failures and responsibilities that causes these failures. Further, forensic engineering could be considered as a fact-finding expertise for identifying responsibilities-related failures [1-8].

Most of studies and researches in the field of forensic structural engineering focus on case studies to present methodologies and procedures for reaching legal-technical decisions. For example, [9] performed a forensic analysis of failure in a block of buildings due to the construction in the vicinity of the block of a car park. The analysis investigated if the observed damage was due to self- deterioration of the building, or it depends on the afterwards construction of the car park. Gayarre, et al. [10] conducted a forensic analysis of a damage occurred on a number of buildings which may have been affected by a reduction in groundwater table, caused by the extraction of water occurred during the construction of

Mohammed Arafa, Civil Engineering Department, Islamic University of Gaza, P.O. Box 108, Gaza, Palestine

Husam Wadi, Université Clermont Auvergne, Institut Pascal, BP 10448, Clermont-Ferrand, France

Mamoun Alqedra, Civil Engineering Department, Islamic University of Gaza, , Gaza, Palestine nearby building basement. Álvarez-Fernández, et al. [11] performed a comprehensive forensic evaluation of time-dependent damages happened to buildings in Spain due to subsidence resulted from nearby mining activities.

Less studies and researches deals with establishing frameworks, systematic procedures, general guidelines, manuals of applying forensic engineering on construction applications. Poulos [12] established a framework to investigate the potential foundation failures resulted from common foundation and geotechnical aspects. Ratay [2] presented an overview of the professional practice of forensic structural engineering by discussing the factors and parameters involved in failures and forensic analysis. His study indicated that there is a need to systemize the forensic structural engineering investigations.

Parisi and Augenti [13] conducted a failure investigation approach based on characterization, modelling and propagation of uncertainties and applied a forensic analysis of a historic piperno stone balcony, the collapse of which induced four casualties. This case study represents a wide use of piperno stone in the architectural heritage of Naples and Southern Italy. This study mainly presents a methodology for probability-based diagnosis and prognosis of structural failures of historical constructions.

Anastasopoulos [14] presented a forensic analysis of a 5 -storey building damaged during construction of an adjacent 4-storey structure. Based on the conducted forensic investigation and numerical analyses, the shear failure of the infill walls of the 5-storey building was mainly due to its design flaws and construction defects. Further, the results of this study showed that the erection of the 4-storey building played an important but secondary factor.

Local authorities, legal bodies and engineering consultants are repeatedly requested to carry out forensic evaluations. Each party has adopted its own strategy and developed its own procedures in an effort to both outline the causes of failure and shed light on which party might be responsible. This is due to the absence of a well-shaped framework to conduct forensic investigation associated with reinforced concrete structures. In addition, no particular guidelines are yet available which have at their heart highlighting the responsibilities that cause these damages. Therefore, the authors believe that there is a need to systemize the available experience of forensic structural engineering through establishing manuals or frameworks, which would guide and assist the forensic engineers to undertake their duties.

This study aims at developing a forensic framework for conducting forensic evaluation of failures occurred in reinforced concrete structures; such framework would support engineers in assessing forensic structural failures. The development of this framework requires systemizing the stages and procedures of forensic investigations related to reinforced concrete buildings, connecting them with legal responsibilities and validating the developed framework. 


\section{ESTABLISHING A FORENSIC STRUCTURAL FRAMEWORK}

The developed Forensic Structural framework would enable engineers in conducting forensic investigations for buildings. The developed FSF seeks to implement the best forensic practices within engineering investigation relevant to all types of failure occurred in reinforced concrete structures. An effective forensic framework should be simple and straightforward, represent all causes of failure in reinforced concrete structure and include corresponding legal responsibilities. Such framework requires well-experienced to assess conditions of the structure, identify the causes of damage and determine acts that lay the template for the failure, thereby enable Outlining major and minor responsibilities of the failure. The suggested framework, shown in Figure 1, comprises five stages, as follows:

1- Preliminary Stage,

2- Evidence Collection Stage,

3- Failure Hypotheses and Analysis Stage,

4- Conclusion Stage,

5- Responsibilities Assigning Stage.

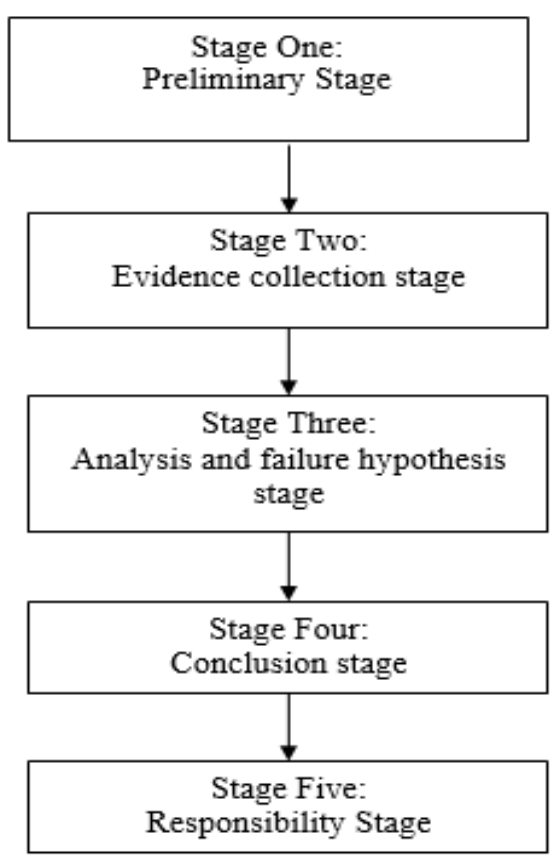

Each stage of the framework comprises several steps

Figure 1: Stages of the proposed comprising several tasks in order to achieve the objective of this stage. Figure 2 presents the full version of the developed FS framework. The following paragraphs explain in more details the stages of the framework.

\section{DESCRIPTION OF THE FRAMEWORK STAGES}

\section{A. Preliminary Stage}

During the preliminary stage, the necessary information and data related to building is collected and all related documents are reviewed. Further, the preliminary stage includes setting the plan of the investigation of the failure.

\section{B. Evidence Collection Stage,}

The second stage comprises collection of evidences. The investigators should conduct site visits as early as possible in order to eliminate any disturbance to the evidence. In turn, the site visit involves three components, as shown in Figure 2 , namely visual inspection, eyewitness information and sample collection. Efficient visual inspection and availability of possible eyewitness' information would ease the process of collection of the samples. Through visual inspection, investigators are able observe the failure scene, thereby providing the main evidence that may report about how the failure occur. On the other, investigators while communicating to eyewitnesses on site seek to understand the actual modes and sequences of failure because eyewitnesses would often provide valuable evidence to investigators. Collecting samples relevant to the failure is also a significant step because it may reveal important evidence. The data collectively obtained at the site visit may shed light on the initial failure hypothesis to be examined at the third stage. 


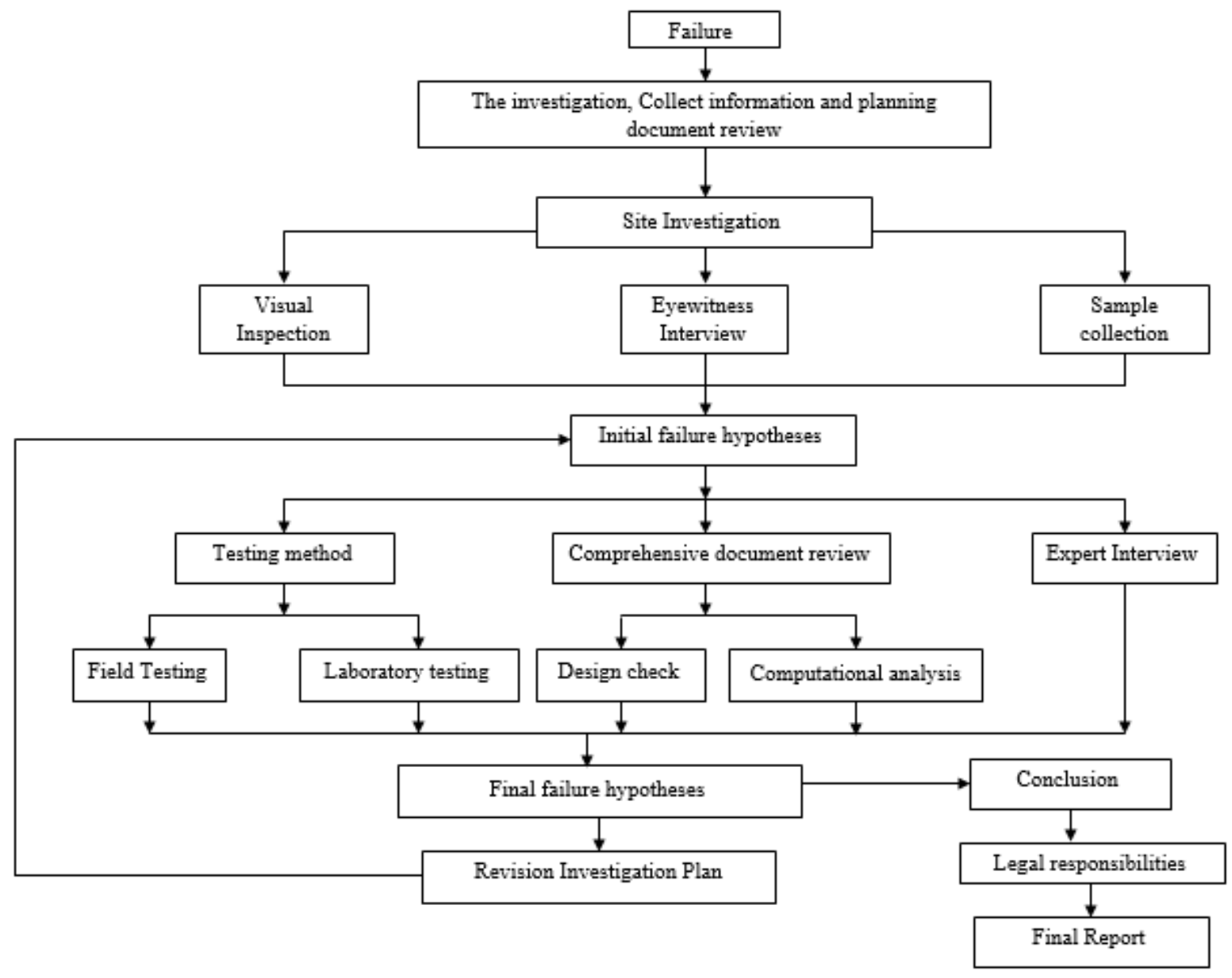

Figure 2: The developed FS framework

\section{Failure Hypothesis and Analysis Stage}

The third stage, failure hypotheses and their analysis, discusses and approves the data obtained previously. It comprises three approaches: carrying out testing methods, a critical review of relevant documents and, lastly, conducting depth interviews, as shown in Figure 2. The testing methods are categorized as field and laboratory assessments, involving a series of non-destructive and destructive that will be carried out on site. The key purpose is to check the actual mechanism of concrete structure. Laboratory, on the other, involves specific tests that are commonly destructive in an attempt to examine capacity and mechanism of certain components of concrete structure. It may also involve chemical analysis, loading tests and other associated testing.

The review of documents involves also 'Design check' and 'computational analyses. The former includes the review of relevant documents related to the failure. By reviewing the documents, the investigators will be more familiar with the case and any discrepancies that will be detected. Computational analysis is a recommended procedure using relevant software packages to analyze the concrete structure. A supplementary approach is therefore adopted in an effort to prove the 'failure hypothesis', for example using semi-structured interviews. In addition, an expert's expertise may also help prove the 'failure hypothesis', hence offering valuable explanations to the investigators towards understanding the cause of the failure. Upon completion of all analysis, work could be undertaken to test the 'failure hypotheses.

\section{Conclusion stage}

The fourth stage is the conclusion stage in which specific interpretations are drawn, namely from the findings derived from the evidences obtained which in turn lay the template for the causes of failure.

\section{E. Responsibilities assigning stage}

The final stage is the responsibilities assigning stage during which the major and minor responsibilities are assigned to the relevant parties, i.e. the contractor, engineers and owner. It is recommended that specific civil responsibilities law, local or international, should be considered during this stage. For example, the Egyptian law states that the major responsibility of failures and/or errors occurred in the design is assigned at the designer. However, during construction, major responsibility is assigned at the contractor and minor responsibility is assigned at supervision engineer.

\section{COMPARISON WITH AVAILABLE FRAMEWORKS}

The framework suggested by [12] was set out specifically for forensic geotechnical assessments of foundation failures. This framework is relatively simple and indicates a systematic consideration of the various factors that may have involved in such failures. Poulos [12] framework includes a group of questions, which need to be addressed. By addressing these questions, one or more valid hypotheses would be formulated. A comparison between the current framework and Poulos framework is presented in Table 1. 
Developing a Forensic Framework for Failures in Reinforced Concrete Buildings

Table 1. Comparison between the current and Poulos frameworks

\begin{tabular}{|c|c|c|c|}
\hline o. & Items & Current framework & Poulos framework \\
\hline 1 & Preliminary Stage & Planning and document review & Planning and document review \\
\hline \multirow{3}{*}{2} & \multirow{3}{*}{ Evidence collection stage } & Visual inspection & $\begin{array}{l}\text { Visual inspection } \quad \text { using } \\
\text { True/false checklist }\end{array}$ \\
\hline & & Eyewitness Interview & ---- \\
\hline & & Sample collection & Sample collection \\
\hline \multirow{4}{*}{3} & \multirow{4}{*}{$\begin{array}{l}\text { failure hypothesis and } \\
\text { analysis stage }\end{array}$} & Initial failure hypotheses & Initial failure hypotheses \\
\hline & & Testing method & Testing method \\
\hline & & Document review & Document review \\
\hline & & Expert interview & ---- \\
\hline 4 & Conclusion stage & Final failure hypotheses & Final failure hypotheses \\
\hline 5 & Responsibilities stage & $\begin{array}{ccc}\text { Contracts' } & \text { and } & \text { engineers' } \\
\text { responsibilities }\end{array}$ & ------- \\
\hline 6 & $\begin{array}{l}\text { Specific guidelines for } \\
\text { investigation }\end{array}$ & $\begin{array}{l}\text { Guidelines for visual inspection } \\
\text { and site investigation }\end{array}$ & ------- \\
\hline
\end{tabular}

Table 1. indicates that the current framework agree very well with that suggested by [12]. However, Poulos framework does not include any legal aspects in his framework. This short come does not exist in the current framework, as it comprises specific stages related to the legal aspects.

\section{CASE STUdy}

This developed framework was applied to a documented local failure case. The local failure case was the collapse of Abu Baker Alsedeq roof slab in 2017, Jabalia City, the Gaza Strip, Palestine. A forensic team was formed to investigate the case and identify the causes of failure and the legal responsibilities.

The project was construction of a three stories mosque building with a basement area of $70 \mathrm{~m}^{2}$, the ground floor with an area $400 \mathrm{~m}^{2}$ for the male prayers. The first floor is for the female prayers with an area of $200 \mathrm{~m}^{2}$. The building comprises also a $36 \mathrm{~m}$ minaret, a main dome and several small domes. The management board of the project comprised a consulting supervision firm with a full-time site manager, site engineer, part-time electrical and mechanical engineer. In addition, the contractor was required to provide the required technical staff.

The shuttering of the reinforced concrete ribbed slab of the $8.5 \mathrm{~m}$ height first floor of the mosque was started as per the approved plan. The works were continuously inspected by the consulting firm staff and daily comments were given to the contractor. Having issued the "permission to cast" by the consulting site manager, the contractor started the casting process of the first floor reinforced concrete slab of the mosque. The process of casting was proceeding as planned and the dropped slab beams were first gradually filled up by concrete. Having completed the slab beams, the final stage of the casting process was approached, which included the casting of the topping layer of the ribbed slab. After completing about $75 \%$ of the topping layer of the slab, a sudden collapse of the supporting steel posts for about 200 $\mathrm{m}^{2}$ of the casted slab. About $400 \mathrm{~m}^{2}$ of the concrete slab was collapsed; one worker was lost and several casualties' workers were resulted from this accident, in addition to large financial losses.

The forensic team applied the current developed forensic framework by following the five stages of the framework, as descripted in the following sections.

\section{A. Preliminary stage}

In the preliminary stage, design and shop drawings, calculation sheets, daily instruction sheets, monthly reports, material orders and inspections, approved time schedule, soil reports, material test results, daily photos and any relevant documents were obtained and reviewed carefully.

\section{B. Evidence Collection stage}

This stage comprised several steps and procedures, namely: visual inspection, eyewitness interview and sample collection.

\section{Visual inspection}

The forensic team have conducted several visual inspection visits in order recognize the extent of commitment of the contractor with the approved work plan and technical specifications. Figure 2 presents some photos of the failure of the mosque.

\section{Sample Collection}

The forensic team collected randomly several samples of the circular hollow steel posts (single size and double size posts) and the steel post connections. These samples were sent to an accredited local laboratory to obtain the outer diameter, inner diameter, wall thickness, uniformity of the thickness along the length, existence of corrosion, etc. 


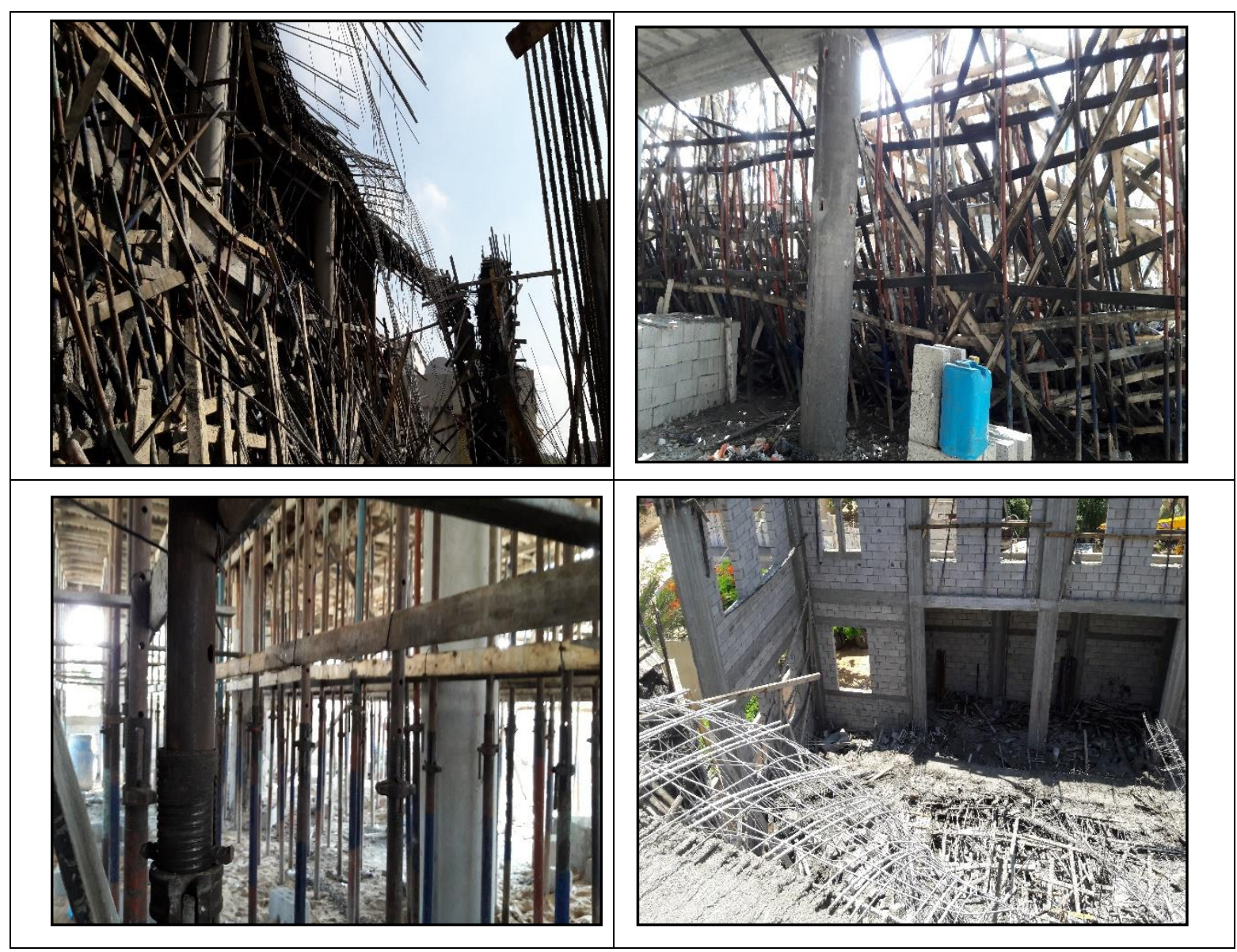

Figure 3: Photos of the failure of Abu Baker mosque.

\section{E. Eye Witness Interviews}

The forensic team interviewed the contractor engineer, supervision engineer, the shuttering subcontractor in order to take their statements regarding the cause of the failure.

\section{$i$. Statement of the Supervision Engineer}

The supervision engineer stated that after finishing all shuttering works including the supporting steel posts in two dimensions, the consulting site manager carried out a final inspection of the shuttering works and requested the contractor to replace some of the steel posts, provide more posts in certain locations, and increase the horizontal supports and extend it to reach a fixed positions. Afterwards, the consulting engineer approved the request for casting submitted by the contractor. The supervision site manager mentioned that after finishing about $70 \%$ of the slab area and when started casting the topping layer of the slab, the collapse suddenly occurred without noticing any deflection or deformation of the shuttering works.

\section{ii. Contractor Engineer Statement}

The contractor engineer stated that they took all required technical and safety procedures for the shuttering works before the commencement of the casting process through installing additional supporting posts between the existing ones in the wide spaces between the steel posts. He also mentioned that the supporting steel posts were continuously inspected during the casting process. He did not find any defect in these supporting posts. He added that the collapse occurred before the end of the casting process and happened suddenly with any indications.

iii. The shuttering Subcontractor

The subcontractor stressed that all supporting system elements were safe, adequate and up to the standards for such works and he took all procedures and comments given by the consulting team. He added that he did not notice any failure or malfunction in the works. He mentioned that the same shuttering system was applied in similar projects and no problems were occurred.

\section{F. Failure Hypotheses and Analysis Stage}

The forensic team has set four hypotheses for the failure in order to reach what was went wrong and identify the legal responsibilities. The following paragraphs present the details of these hypotheses and their analysis to reach the most likely cause of collapse.

\section{i.Deliberate Criminal Action.}

The Criminal Evidence Service conducted a technical criminal investigation to examine possible causes of the failure by examining the site, documenting the scene of the event, looking for evidence of any criminal suspicion by questioning the site guard and the office boy. They looked for evidence of any kind of explosions or tremors at the event site or near of the site.

The investigation, which was carried out by the Criminal Evidence Service, concluded that there was no intentional or unintentional criminal suspicion of the incident and concluded that no explosions or large vibrations occurred at or near the site. Consequently, the forensic team excluded this hypothesis.

\section{ii. Inadequate Applied Supporting System}

The use of the single steel post support system is one of the most popular and widely used systems. This is due to the fact 
it is an easy-to use-system and the only available one in the Gaza Strip. This is system is limited to heights of up to $5 \mathrm{~m}$. This limitation forced the contractors to install two or more of these posts on top of each other to achieve heights above $5 \mathrm{~m}$. Such supporting system (more than one layer of posts) includes several weaknesses and risks that could cause problems, for example the weak interconnection between these layers. In the current case, two supporting layers were installed to reach the required $8.5 \mathrm{~m}$ height; each layer of support was about $4.25 \mathrm{~m}$ height.

The investigation, which carried out by the forensic team during the evidence collection stage, concluded that the contractor committed to the approved working plan and the technical specifications of the project. The contractor applied the approved spacing between the posts based on the calculation sheet of the floor loads and the bearing capacity of each steel post.

The calculations carried out by the forensic team revealed that the bearing capacity of each steel post is $1800 \mathrm{~kg} / \mathrm{m}^{2}$; the applied load imposed on the floor is $1062 \mathrm{~kg} / \mathrm{m}^{2}$. Based on applied load and the bearing capacity of the steel post, the design spacing between the posts should be not more than $90 \mathrm{~cm} \times 90 \mathrm{~cm}$. The visual inspection revealed that the spacing between the posts ranged between $70 \mathrm{~cm}$ to $90 \mathrm{~cm}$. The total load resulting from the main $60 \mathrm{~m}$ wide dropped beam is 2092 $\mathrm{kg} / \mathrm{m}^{2}$.

The revision of the approved work plan and the eyewitnesses indicated that three steel posts were installed along the width of the dropped beams with $40 \mathrm{~cm}$ spacing between each of these three posts. This means that the three posts collectively receive $0.40 \times 2092 \mathrm{~kg} / \mathrm{m}^{2}=837 \mathrm{~kg}$. Accordingly, each of the three steel posts receive one third of the $837 \mathrm{~kg}$, which far less than the bearing capacity of the steel posts.

There was no indication of any defect in the results of the soil capacity. There were no cracks nor damages observed in the ground floor underneath the posts after removing the debris. All concrete test results of all structural elements were according to the technical specifications. The forensic team concluded that this hypothesis is not valid and consequently this hypothesis is excluded.

\section{iii. Existence of unseen defects in the used roof supports}

It is known that there are many steel components forming the single post roof supporting system. The main element of the system comprises a three inches hollow circular steel post with a thickness not less than $2.5 \mathrm{~mm}$. This steel post has also another circular steel post, which goes inside it; the inner pipe is used to adjust the height of the post. To ensure that the 3 " hollow steel post is fixed with the inner post, threaded collar is provided and $12 \mathrm{~mm}$ holes facing each other are made to allow steel bars to pass through the outer and inner posts in order to connect them. The installation of such supporting posts requires high skills in assembling, fixing lacing etc. Therefore, the installation process could have many problems and defects as follows:

- Existence of unseen wear off, corrosion and rust in some of the used supporting posts. These defects could be difficult to discover due to the painting.

- Variations in post wall thickness, which could not be easily, distinguish between by naked eye.

- Existence of wear off in the threads of some of the posts. This could be very dangerous as it prevents the posts from performing properly.
- Existence of buckling and/or deformation in the used steel posts.

- Absence of the bottom post base.

- Crookedness and misalignment of the steel posts and bad distribution of the posts according to the approved spaces and approved work plan.

Therefore, the existence of such defects in the installed supporting posts and its components could be a valid cause of the failure.

From the samples collections, steel posts with thickness of $2.0 \mathrm{~mm}, 2.2 \mathrm{~mm}$ and $2.3 \mathrm{~mm}$, were found. Some of the used steel posts suffer from wear off in the threads area and other posts have deep corrosions. These defects definitely reduced significantly the bearing capacity of these steel posts. Further, the verticality of several of the posts was not maintained, especially along the layers of the supporting system. In addition, some posts suffer from clear crookedness and buckling. Based on these findings, the forensic team concluded that this hypothesis is highly valid to be the cause of the failure

iv. '

The casting of the top layer of the ripped slab was the final stage. However, this stage is considered one of the most important and most dangerous stage. This is because the casting process and the distribution of concrete on the roof requires a proper mechanism in order to avoid developing unbalanced weights during casting. Creating unbalanced weight could be a valid cause of the failure. As the eye witnesses stated that the failure occurred after about $75 \%$ of topping slab was completed.

Based on the eyewitnesses' statements, they stated that the contractor committed to provide and cast the concrete based on the approved method of statements of concrete casting. The casting was carried out gradually for the main dropped beams. Having completed the casting of the beams, the contractor started casting thee topping layer. The forensic team concluded that the applied casting process could be responsible for the failure through developing some unbalanced weights.

\section{G. Case Conclusion}

In conclusion, the forensic team concluded that the main cause of failure would mainly be referred to the unseen defects in the used materials including the main supporting steel posts. In addition, the failure was triggered by the development of a state of unbalanced weights when casting of the topping layer started.

\section{H. Responsibilities Assigning Stage.}

Based on the case conclusion that the main cause of collapse was due to defects in the used supporting steel posts. The installation and performance of such posts are of the major tasks of the contractor who should take the major responsibilities for any failure in these supporting posts. In addition, the consulting site manger takes a minor responsibility because he/she should have disapproved such material to be used. Therefore, the forensic team concluded that contractor and its insurance company should bear the legal and financial consequences of the collapse. [9]

\section{CONCLUSIONS}

The current study developed a forensic framework for conducting forensic structural evaluation of failures occurred 
in reinforced concrete structures; existence of such framework would assist engineers in investigating building failures. The framework outlines the procedures required to conduct the investigation for the causes of failures of reinforced concrete buildings and identify the legal responsibilities.

The established framework comprises five stages; each stage consists of several steps to contain as many factors and parameters involved in identifying failures and their causes. This five stages framework comprise preliminary stage, evidence collection stage, analysis of failure hypotheses stage, conclusion stage and responsibilities assigning stage. One of the main benefits of the developed framework is the fact that the legal responsibilities stage are connected to causes of failure through evidence based-facts. The current forensic framework was applied to local collapse case as a validation step. The application of the suggested framework to the local collapse case proved that the framework was comprehensive and effective in reaching the causes of failure and assigning legal responsibilities in a systematic procedure.

\section{REFERENCES}

[1] R. K. Noon, Forensic engineering investigation. CRC Press, 2000.

[2] R. T. Ratay, "An Overview of Forensic Structural Engineering," Structural Engineering International, vol. 27, no. 3, pp. 338-343, 2017.

[3] E. Brown, "Forensic engineering for underground construction," in Rock Mechanics In Underground Construction: (With CD-ROM): World Scientific, 2006, pp. 3-18.

[4] J. B. Kardon, "Guidelines for forensic engineering practice," 2012: ASCE.

[5] R. T. Ratay, Forensic structural engineering handbook. McGraw-Hill New York, 2010.

[6] K. L. Carper, Forensic Engineering, Second Edition ed. CRC Press 2000 .

[7] C. Madryas, "Forensic investigations of buried utilities failures in Poland," Tunnelling and Underground Space Technology, vol. 23, no. 2, pp. 199-205, 2008

[8] R. Juárez-Ferreras, C. González-Nicieza, A. Menéndez-Díaz, A. E. Álvarez-Vigil, and M. I. Álvarez-Fernández, "Forensic analysis of hydraulic props in longwall workings," Engineering Failure Analysis, vol. 16, no. 7, pp. 2357-2370, 2009.

[9] C. González-Nicieza, M. I. Álvarez-Fernández, A. E. Álvarez-Vigil, and A. Menéndez-Díaz, "Forensic analysis of foundation failure in gypsiferous ground," Engineering Failure Analysis, vol. 15, no. 6, pp. 736-754, 2008.

[10] F. L. Gayarre, C. González-Nicieza, M. I. Alvarez-Fernández, and A. E. Álvarez-Vigil, "Forensic analysis of a pile foundation failure," Engineering Failure Analysis, vol. 17, no. 2, pp. 486-497, 2010.

[11] M. I. Álvarez-Fernández, A. E. Álvarez-Vigil, C. González-Nicieza, and F. L. Gayarre, "Forensic evaluation of building damage using subsidence simulations," Engineering Failure Analysis, vol. 18, no. 5, pp. 1295-1307, 2011.

[12] H. Poulos, "A framework for forensic foundation engineering," in Forensic Geotechnical Engineering: Springer, 2016, pp. 1-15.

[13] F. Parisi and N. Augenti, "Structural failure investigations through probabilistic nonlinear finite element analysis: Methodology and application," Engineering Failure Analysis, vol. 80, pp. 386-402, 2017.

[14] I. Anastasopoulos, "Building damage during nearby construction: Forensic analysis," Engineering Failure Analysis, vol. 34, pp. 252-267, 2013. 